\title{
Bases de datos de libre acceso difundidas por la Administración General del Estado (L. Fernando Ramos-Simón)
}

\author{
Por Antonio Muñoz-Cañavate
}

Muñoz-Cañavate, Antonio. "Bases de datos de libre acceso difundidas por la Administración General del Estado (L. Fernando Ramos Simón) (reseña de libro)”. El profesional de la información, 2009, julio-agosto, v. 18, n. 4, pp. $475-477$.

DOI: $10.3145 /$ epi.2009.jul.19

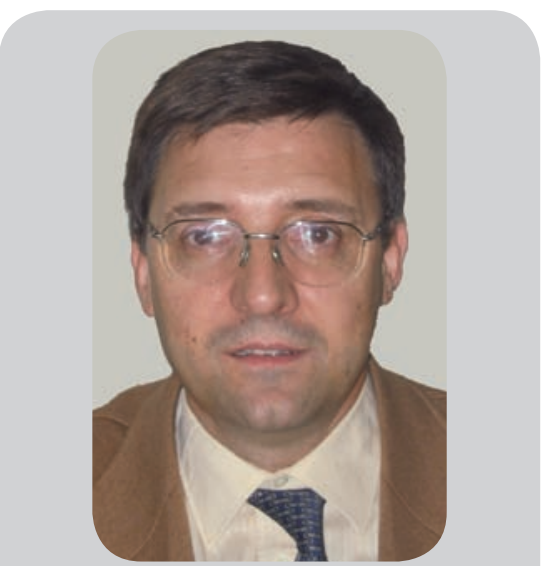

Luis Fernando Ramos Simón es catedrático de escuela universitaria de la Facultad de Ciencias de la Documentación de la Universidad Complutense de Madrid (UCM) y, en la actualidad, decano del Centro, donde imparte docencia sobre Administración y márketing de unidades de información. Es doctor en Ciencias de la Información por la UCM desde 1988, en esta Universidad se licenció en Periodismo (1979) y en Derecho (1980). Coordina el Grupo de Investigación Publidoc, reconocido por la Comunidad de Madrid (940589) y especializado en gestión de la información y documentación en el sector público, formado por ocho profesores del área de Documentación y Archivística. El Grupo ha trabajado en varios proyectos competitivos concedidos por el $M \stackrel{0}{0}$ de Ciencia e Innovación, la Comunidad de Madrid, la UCM y el Banco de Santander, así como en algunos contratos de investigación. Es autor de artículos y monografías, entre ellas "Introducción a la administración de información" y "Dirección, administración y márketing de empresas e instituciones documentales".

EN DICIEMBRE DE 2008 aparecía la obra 'Bases de datos de libre acceso difundidas por la Administración General del Estado" realizada por el Grupo Publidoc (grupo de investigación dedicado a la gestión de la información en el sector público) de la Universidad
Complutense de Madrid, al frente del cual se encuentra el profesor Luis Fernando Ramos Simón, coeditada por la Dirección General del Libro, Archivo y Bibliotecas del Ministerio de Cultura y por la Editorial Complutense.

La guía viene a cubrir un importante hueco que era necesario rellenar, y esperamos que puedan aparecer en el futuro nuevas ediciones actualizadas, en tanto que los contenidos de este trabajo experimentan cambios y crecimientos continuos. Hay que recordar como precedentes los directorios que hasta mediados de los años noventa publicó Fundesco con diversos catálogos sobre los servicios españoles de información electrónica ascii, y los servicios Ibertex, o los directorios de bases de datos de la Administración publicadas por el Ministerio de Administraciones Públicas en esa época ${ }^{1}$.

La gestión de información del sector público ha comenzado a convertirse afortunadamente en materia de enseñanza e investigación en los estudios de información y documentación. Esto permite asegurar que durante los próximos años grupos como el de la Universidad Complutense puedan asentar líneas de trabajo que aborden el control de esa información pública a la que se accede a través de bases de datos, además de toda la amalgama de factores que la rodean. Entre estos, se pueden citar las políticas de información puestas en marcha desde el sector público, y con ello una legislación novedosa

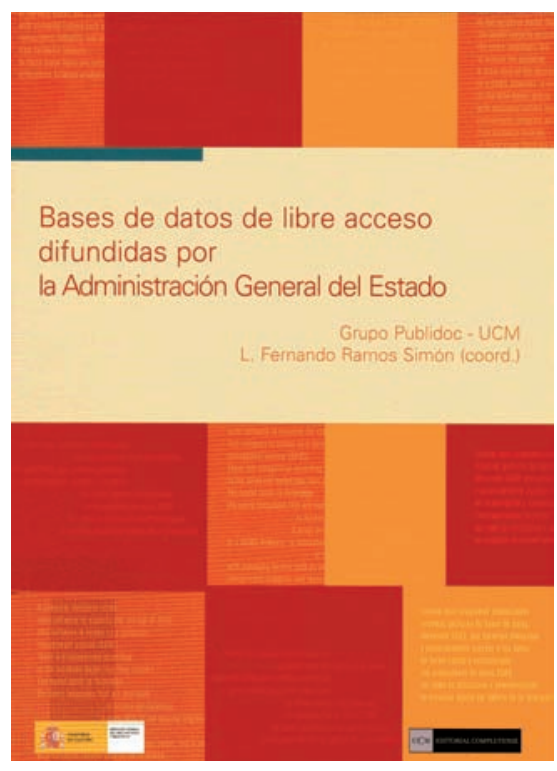

Ramos-Simón, L. Fernando. Bases de datos de libre acceso difundidas por la Administración General del Estado.

Grupo Publidoc-UCM, coord. Madrid: Ministerio de Cultura, Editorial Complutense, 2008, 349 pp.

ISBN 978-84-7491-940-0

que es necesario conocer y que enlaza con las nuevas formas de administración pública: la administración electrónica.

La información del sector público implica también un nuevo modelo de comunicación con los ciudadanos en tanto que se adentra en la transparencia de las propias instituciones, y en este sentido no hay que olvidar que estos avances se observan ya en Europa desde el propio Tratado de 
"La información recogida por las administraciones como consecuencia de su gestión es la materia prima para muchos productos y servicios digitales que pueden elaborar y comercializar las empresas"

\section{Maastricht (1992) o el Tratado de Amsterdam (1997).}

En los años ochenta tenemos algunos precedentes como el intento de la Comisión Europea a través del Programa Impact para crear un mercado de la información. En los noventa la Comisión elaboró el documento "La información del sector público: un recurso clave para Europa", más conocido como el Libro Verde de la información en el sector público, que publicó en 1998. En el mismo se decía que esta información desempeña un papel fundamental para el buen funcionamiento del mercado interior y para la libre circulación de mercancías y personas" y que "la información pública en Europa se encuentra fragmentada y dispersa, de tal forma que "de lo que se trata no es de que los Estados miembros produzcan más información, sino de que la información que ya está disponible para el público sea más clara y accesible a sus usuarios potenciales".

Aquel Libro Verde inspirará años después la Directiva 2003/98/CE de 17 de noviembre relativa a la reutilización de la información del sector público ${ }^{2}$. En la misma se dice que este sector recoge, produce, recopila y difunde una amplia gama de información relativa a numerosos ámbitos: social, económica, geográfica, meteorológica o turística, además de información sobre empresas, patentes y educación, y que, a su vez, esta información constituye la materia prima para productos y servicios digitales, de tal manera que si los orga- nismos del sector público gestionan estos documentos, su utilización por otros motivos constituye una reutilización.

La aplicación de dicha directiva a España da lugar a la promulgación de la Ley 37/2007 sobre reutilización de la información del sector públi$\mathrm{Co}^{3}$, que si bien no modifica el régimen de acceso a los documentos administrativos consagrado en el ordenamiento jurídico español, aporta un valor añadido al derecho de acceso, y prevé que las diferentes administraciones difundan la documentación susceptible de ser reutilizada a través de la creación de listados e índices accesibles en línea de los documentos disponibles.

En este contexto surge en Europa la Red europea de promoción de la reutilización de información pública (Epsiplus) en 2006 dentro del programa eContentplus de la $U E$.

En España se han realizado recientemente algunos eventos como el encuentro realizado en Barcelona el 30 de junio de 2008 Public sector information re-use in Spain, o el del 24 de octubre de 2008 Primera jornada sobre reutilización de la información de sector público: estado de la cuestión que organizó el Grupo Publidoc-UCM, y en el que participaron ponentes de la $U E$, además de representantes de diferentes ministerios y empresas.

A su vez, dentro del Plan Avanza 2, aparece el proyecto Aporta ${ }^{4}$ cuyo objetivo es el de situar a España en vanguardia europea en materia de reutilización de la información del sector público, y que se enmarca en la Conferencia Ministerial sobre el Futuro de la Economía de internet de la $O C D E$ que se celebró en junio de 2008 en Seúl. En esta conferencia se aprobó la "Recomendación para el mejor acceso y el efectivo uso de la información pública" que entre otros aspectos recomienda a los estados miembros fomentar la disponibilidad de esta información para su uso y reutilización, de tal manera que se asuma como principio la apertura de la información pública, a garantizar la recopilación y conservación metodológica de datos para mejorar la calidad y fiabilidad, lo cual incluye la cooperación con diversos organismos, y el fomento del uso de las nuevas tecnologías para acceder a la información que genera, lo cual supone mejorar las tecnologías de almacenamiento, búsqueda y selección.

Son numerosos los ejemplos que se pueden poner acerca de la generación de servicios y productos de valor añadido con la información del sector público. El proyecto Aporta menciona algunos, como en el ámbito de la información meteorológica, las predicciones meteorológicas personalizadas; las recopilaciones de legislación y jurisprudencia; los sistemas de navegación de los automóviles y la información cartográfica digital; la información sobre subvenciones; la información turística; los estudios económicos; la información sobre tráfico, etc.

\section{EI libro}

Si bien la parte más importante de la obra se compone, como no podía ser de otra forma, por las fichas descriptivas de las bases de datos de libre acceso en internet de la Administración General del Estado (AGE), el volumen dispone de una primera parte titulada "Metodología de trabajo y análisis general de la reutilización de información de libre acceso de la AGE" que conviene leer con detenimiento y en la que Iuliana Botezán, Concepción Mendo y Rosario Arquero analizan diversos aspectos de las políticas referentes a la información del sector público, las bases de datos de la AGE, y, por supuesto, la metodología empleada en la localización, identificación y análisis de las bases de datos.

Botezán desarrolla una introducción a la directiva 2003/98 ya citada antes y la correspondiente Ley española de 2007. Pone de manifiesto que no existe un organismo 
nacional cuya función sea la de velar por el cumplimiento de la normativa que transpone la Directiva, por lo que muchos actores del sector de la reutilización ven limitadas sus posibilidades en tanto que no pueden aprovecharse de las oportunidades que proporciona el nuevo marco.

Otro de los problemas planteados es la falta de conocimiento de toda esta información, ya que el modelo de islas de información impide que el sector privado conozca los repositorios, y pueda realizar propuestas comerciales de reutilización.

Concepción Mendo señala qué organismos de la AGE se han convertido en objeto de este trabajo. La compleja Administración del Estado se rige en su organización, funcionamiento y actuación por la Ley de Organización y Funcionamiento de la Administración General del Estado (Lofage) que incluye en su amplia organización a los organismos autónomos y a las entidades públicas empresariales, estas últimas quedan excluidas de esta obra.

El apartado de la profesora Mendo incluye un cuadro con una lista de todos los organismos autónomos y agencias de la AGE, además de otras entidades de derecho público que sí han sido objeto del trabajo.

Por otra parte, Arquero informa que para acotar el material de análisis se ha partido del concepto de base de datos como el recurso de información y documentación específico, de acceso libre y gratuito a través de internet incluido en la web de un ministerio y que puede ser consultado mediante un formulario de búsqueda integrado por una o varias casillas de búsqueda, quedando excluidas las cajas de búsqueda genéricas, como los buscadores globales que aparecen en las páginas de inicio de los ministerios.

El grueso de la obra se compone de las fichas descriptivas de las 509 bases de datos ordenadas por ministerios. La estructura de las fichas, que explica con detalle Rosario Arquero en su apartado, contiene:

- datos de identificación;

- título del recurso;

- organismo editor;

- clase de información (catálogos, censos y directorios, datos estadísticos, datos producidos por el organismo, imágenes, informes, mapas y planos, normas y jurisprudencia, y noticias y actualidad);

- formato de presentación (hoja de cálculo, imagen, imagen y texto, otros o sólo texto);

- tipo de información (referencial, texto completo y enlaces a contenidos);

- tipos de consulta, diferenciando en este caso entre simple -cuando el formulario de consulta de la base de datos presenta una única casilla de búsqueda-, o avanzada -cuando el formulario de consulta presenta más de una casilla-;

- materias;

- breve descripción y comentario de cada base de datos.

Este bloque se presenta con una relación detallada de las bases de datos por ministerios, y de dos índices, de los organismos editores y de las materias, que permite localizar todas las bases de datos de un aspecto específico, independientemente del organismo editor.

El modelo español de estado de las autonomías da lugar a que el campo de actuación en el ámbito de la información del sector público sea mucho mayor que el de los países de nuestro entorno, en tanto que se hace necesario controlar las numerosas bases de datos creadas en las distintas autonomías españolas. Parece lógico pensar que se hace necesario publicar las guías de las bases de datos que han creado las administraciones autonómica y local. Así, una guía que incluya no sólo a los más de 8.000 ayuntamientos (o al menos los 721 con más de 10.000 habitan- tes), sino también a las diputaciones provinciales, cabildos y consells insulars, sería una herramienta muy útil, por ejemplo, para la toma de decisiones en el ámbito empresarial y en general de todo tipo de organizaciones, uniendo información del sector público e inteligencia competitiva.

De hecho el propio coordinador de este libro, el profesor Ramos Simón, nos dice en la presentación de la obra que los siguientes pasos que se propone dar el grupo se orientan a profundizar en el inventario de los actores de información en otros formatos diferentes a las bases de datos y en otros organismos del sector público (poder judicial, legislativo, o las administraciones autonómicas y locales, así como del resto de la administración central).

Además de los autores ya citados, forman parte del Grupo como responsables de esta obra los doctores y profesores de la Universidad Complutense, Jaime Peón-Pérez, Rodrigo Sánchez-Jiménez, Carlos Tejada-Artigas y Félix del ValleGastaminza.

\section{Notas}

1. Ministerio para las Administraciones Públicas, Ministerio de la Presidencia. Directorio de servicios de información electrónica de la Administración general del Estado. Madrid: Boletín Oficial del Estado, 1995, 615 pp. ISBN 84-340-0767-3

2. Directiva 2003/98/CE del Parlamento Europeo y del Consejo de 17 de noviembre de 2003 relativa a la reutilización de la información del sector público.

http://ec.europa.eu/information_society/policy/ psi/docs/pdfs/directive/psi_directive_es.pdf

3. Ley 37/2007, de 16 de noviembre, sobre reutilización de la información del sector público. http://www.boe.es/boe/dias/2007/11/17/pdfs/ A47160-47165.pdf

4. Proyecto Aporta (Plan Avanza 2).

http://www.aporta.es/

Antonio Muñoz-Cañavate, Departamento de Información y Comunicación, Universidad de Extremadura.

amunoz@alcazaba.unex.es 